Fakultät III

Wirtschaftswissenschaften, Wirtschaftsinformatik und Wirtschaftsrecht

Volkswirtschaftliche Diskussionsbeiträge

Discussion Papers in Economics

No. $181-17$

January 2017

Carsten Hefeker - Michael Neugart

Non-cooperative and Cooperative Policy Reforms under Uncertainty and Spillovers 
Universität Siegen

Fakultät III

Wirtschaftswissenschaften, Wirtschaftsinformatik und Wirtschaftsrecht

Fachgebiet Volkswirtschaftslehre

Unteres Schloß 3

D-57068 Siegen

Germany

http://www.wiwi.uni-siegen.de/vwl/

ISSN 1869-0211

Available for free from the University of Siegen website at

http://www.wiwi.uni-siegen.de/vwl/research/diskussionsbeitraege/

Discussion Papers in Economics of the University of Siegen are indexed in RePEc and can be downloaded free of charge from the following website:

http://ideas.repec.org/s/sie/siegen.html 


\title{
Non-cooperative and Cooperative Policy Reforms under Uncertainty and Spillovers
}

\author{
Carsten Hefeker* and Michael Neugart ${ }^{\dagger}$
}

January 2017

\begin{abstract}
When countries need to implement costly economic policy reforms, these often imply uncertainties about their effectiveness for the home country and their spillovers to other countries. We develop a model to show that under these circumstances countries implement too few or too many policy reforms. From a social perspective, too many reforms follow if the spillover effects of reforms become sufficiently uncertain. Since centralization of policies to correct inefficient policies is often not possible, we look for alternative instruments that can restore the efficient level of reforms. We compare subsidizing reform efforts with insuring against bad outcomes, and argue that subsidies are advantageous in terms of requiring less information for implementation.
\end{abstract}

JEL classification: F55, H70, O30.

Keywords: Policy reforms, spillovers, policy uncertainty, free-riding, subsidy, insurance

\footnotetext{
${ }^{*}$ University of Siegen, 57068 Siegen, Germany, and CESifo. Email: carsten.hefeker@uni-siegen.de.

${ }^{\dagger}$ Technical University of Darmstadt, 64283 Darmstadt, Germany. Email: neugart@vwl.tu-darmstadt.de.
} 


\section{Introduction}

Setting the right kind of economic policy becomes ever more difficult in an increasingly interdependent and uncertain world. The integration of new regions and countries in the world economy, higher volatility of commodity prices, or an increasing pace of financial and technical innovations require individual countries constantly to adapt their structural policies to a changing set of circumstances or to large scale economic shocks like the global financial and economic crisis. Yet, the impression is that countries do not implement policy changes or reforms to the extent desirable. Moreover, the effect of reforms is highly uncertain. In fact, Babeckỳ and Campos (2011) show in their meta analysis of more than 46 studies and 500 estimates that structural reforms undertaken in recent decades had often variable and even negative outcomes.

Could it be that the interplay of uncertain effectiveness of reforms and countries' economic interdependence is distorting reform efforts? And if so, are there remedies that lead governments to properly reform their countries? To answer these questions, we develop a model of a group of countries where domestic policy reforms have uncertain effects on the output of the reforming and other countries. We show that inefficient levels of policy reforms arise because reforms are costly, outcomes are uncertain, and non-cooperative policies among countries do not take into account uncertain spillover effects. In particular, we demonstrate that policy changes may actually not only be too small but, depending on the size and uncertainty of the spillover effects, may also result in too large an extent of reforms. This would explain why reform policies are often not as successful as expected by policymakers or even fail.

The remedy most often proposed to correct outcomes when externalities distort policy incentives is to harmonize or centralize polices. This, however, often fails in reality because countries are reluctant to give up policy autonomy. A more limited form of policy coordination instead, supported by market instruments and limited fiscal pooling, might have better chances to find common support. Indeed observers have stated that proxies for central- 
ized decision making such as agreements, treaties, accords and other forms of international understandings should be considered (Tanzi, 2008).

Assuming that a directly centralized policy intervention which induces countries to set the "right" level of policy reforms is not possible, we explore how policy choices are changed in the presence of subsidies and insurance. Under the first scheme, policy reforms in a particular country are subsidized by others who benefit from them. This creates an ex-ante incentive for individual countries to pursue more reforms. Second, we explore a mechanism of ex-post redistribution among countries or regions. If "bad" outcomes of policy experiments can be insured by those with "good" outcomes, this provides an incentive to reform more. We derive the optimal amount of subsidies or insurance needed to restore efficiency, and compare the instruments with respect to their implementability.

There are several possible applications of our analysis:

Example 1: Consider European Union member states' labor market reforms to reduce unemployment. States have national autonomy over their labor market policies and are free to pursue different policies to reduce unemployment, such as reducing hiring and firing costs, lowering payroll taxes, allowing more or less migration, or increasing or lowering public spending. However, the outcome of a particular policy measure is often uncertain because the policy is implemented for the first time or, if used elsewhere, because it unfolds differently since its effectiveness depends on the institutional environment of the implementing country if there are complementarities with product markets, the educational system, or the tax system (Coe and Snower, 1997; Freeman, 2005). Moreover, a positive outcome of a policy reform will usually have positive spillover effects to other member states because of increased demand for their products or because of migration. At the same time, labor market reforms are unpopular among the population and thus governments tend to hesitate to implement them. All these factors tend to lead to a sub-optimal level of reforms.

Example 2: Another application for the European case is the discussion about how to deal with the great recession. While some countries advocate more expansive fiscal policies, others weigh against it. One reason for the 
differences in policy proposals is that countries are uncertain about the outcome of more fiscal expansion. While more spending could directly increase output and employment through public investment, others fear that a loss of confidence in financial markets will push countries even deeper into recession. Moreover, it could be that countries in Europe simply try to free-ride on each other's efforts. If policy reform in one country increases its output, others might hope to benefit from this without being forced to implement policy changes themselves. As a consequence, European countries take too few policy measures themselves, instead relying on other countries.

Example 3: A third possible application is the G-20 group of major advanced and emerging market economies. The reduction of excessive current account deficits and surpluses or the regulation of financial markets are also fields where substantial spillover effects exists, where the outcome of particular policy measures are uncertain, where policy reforms are not very popular with the electorates or important interest groups, and where observers lament that national governments are not doing enough (Angeloni and Pisani-Ferry, 2012). Here as well, uncertainty about the outcome of possible reforms, and the attempt to free-ride on the positive spillover effects of other countries' reforms are likely to be an explanation for the observed lack of reform efforts. Example 4: Lastly, global efforts at climate protection have not been very successful so far because such efforts have an uncertain outcome as well as strong spillovers. Arguably, too few measures are taken because countries still dispute the causes of climate change, cannot agree what policy measures are right, and do not want to impose the costs of those policies on their electorate without other countries also implementing climate protection policies. In this case, in particular, it is likely that the free-rider motive dominates other motives because costly climate policies are likely to have very little impact on the reforming country, whereas countries benefit strongly from all others undertaking such policy measures.

In all these examples, as centralized policy setting to improve the collective outcome is apparently not possible, some degree of subsidization or insurance of policy reforms might be capable of yielding more efficient outcomes while being at the same time more acceptable to politicians and na- 
tional electorates than transferring policy sovereignty. Especially in the European case such a fiscal mechanism could build on existing limited fiscal integration in the European Union, and might thus be easier to be agreed upon than in a more heterogeneous groups of countries without a common history of partial integration.

The paper proceeds as follows. The next section connects our paper to the earlier literature, Section 3 develops the model and derives non-cooperative and cooperative policies. Section 4 introduces subsidies and an insurance scheme as instruments to correct inefficient policy choices and evaluates the two mechanisms. Section 5 concludes.

\section{Literature review}

First, our paper is related to the literature on economic reforms and uncertainty. ${ }^{1}$ Several contributions have highlighted the role of uncertainty for the political economy of reforms. A prominent argument advanced in Fernandez and Rodrik (1991) is that when individual agents are uncertain about whether they benefit from a policy reform, they tend to vote against it. Even if the economy as a whole would benefit, promises to compensate losers are not credible, and hence potential losers would never agree to reform. In addition, if reforms are implemented and prove to be negative for a majority, they will be reversed. Another argument is that when there is uncertainty about the welfare improving effects of a reform for the aggregate economy, a gradualist approach can help to make reforms acceptable. Dewatripont and Roland (1995) show that by beginning with those reforms that are likely to yield the highest pay-offs, support for more reforms can be created. This is particularly the case if reforms are complementary and initial reforms become more beneficial if further steps follow. Explaining the role of uncertainty in the delay of reforms has been targeted by Alesina and Drazen (1991). They argue that reforms are delayed as political opponents try to shift the costs of reform policies to the other party and their constituents. In a war of attrition

\footnotetext{
${ }^{1}$ For general surveys, see Roland (2000) or Tommasi and Velasco (1996).
} 
being uncertain about the resources and personal costs of not reforming tends to delay reforms as parties hope that others concede first.

Secondly, our set-up is closely related to the idea of policy spillovers if reforms in one country impact on other countries. Reforms may be induced by factor migration as democratic or economic reforms spill over to neighboring countries when labor and capital can move (Brezis and Verdier, 2003; Gassebner et al., 2011), or when informational spillovers occur as the outcome of policy measures can be observed in neighboring regions (Fidrmuc and Karaja, 2013), implying that policymakers learn and can update their information about expected effects of policy reforms (Meseguer, 2006; Volden et al., 2008; Gilardi, 2010). This builds on theoretical insights of a broader literature that looks at spillover effects from learning (Bala and Goyal, 1998, Bolton and Harris, 1999, Keller et al., 2005), and how this leads to strategic over- and under-experimentation. In those models, policymakers can learn from the choices and outcomes of the policy choices of other policymakers by observing how this policy has affected others and can form more appropriate priors about how a similar policy would affect their own economy. This introduces a strategic component into the framework as adoption of the uncertain policy in the first period reveals its effectiveness in the upcoming period and informs second-period choices, and thereby creates an incentive to wait. This incentive is strongest the more similar countries are because followers learn most in such cases. Mukand and Rodrik (2005) actually show that copying policies is only beneficial for countries whose economic structures are sufficiently similar to those of the country starting with the reforms.

Closely related to the literature on spillovers is work which addresses incentives for policy innovation in federal systems. In particular, the strand which analyzes the incentives to free-ride on policies successfully applied in other jurisdictions (c.f. Rose-Ackerman, 1980) resembles our set-up of strategically interacting governments having to decide on reform efforts. Strumpf (2002) criticizes the most obvious policy remedy to centralize experimentation and argues that a trade-off can arise if central government can only implement a uniform set of policies, whereas lower level governments could find more adequate differentiated policies for their jurisdictions. Kerber and 
Eckardt (2007), and Saam and Kerber (2013) apply the argument to the case of the European Union and conclude that the EU should use more policy experimentation, given the diversity of member states in terms of preferences and institutional set-ups. Thus, centralization is only better if there is a large positive correlation between the sub-level experimental payoffs. Cai et al. (2009) question the unambiguously positive effect of centralization on policy experimentation and argue that centralization may imply too much policy experimentation because not only is free-riding avoided but local office holders cannot be held accountable in this case and thus have an incentive to promote too risky projects. Similarly, free-riding, as argued by Kotsogiannis and Schwager (2006a; 2006b), can cause less under-experimentation if policy experiments increase reelection chances by signaling competence. Empirically, a related effect can be observed in the provision of local goods in the U.S. (Rincke, 2009). The innovation creating effect of yardstick competition seems to be stronger the higher is the chance for local office holders of not being reelected.

Despite the voluminous literature about centralization or decentralization, with a few exceptions little thought has been given to market oriented instruments for policy coordination. Casella (1999; 2001) who studies tradable deficit permits as an alternative to fiscal integration in Europe is one notable exception, and more recently, Callander and Harstad (2015) have developed, as we do, an alternative to centralization. They look into a mechanism in which the role of the central authority is limited to orchestrating a policy tournament between experimenting federal states. They show that an ex-ante announcement that ex-post a winning policy is implemented for all states can be an appropriate design. The negative prize of having to implement another district's policy induces policy experimenting instead of free-riding.

We combine several aspects of the existing literature in our setup. Concerning the level of policy reforms, we combine uncertainty about and spillovers of reforms and show that, if not only the outcome of own policies is uncertain but the transmission of policies onto other countries is uncertain as well, uncoordinated policies can actually lead to too many reforms. This is 
because uncoordinated policies do not take possible adverse effects of own reforms on others into account, and we show when exactly the interaction of uncertainty and spillovers leads to too many or too few reforms. If the uncertainty of the spillover effect relative to its strength is sufficiently large, single countries reform too much compared to a cooperative solution. We also add to the literature the explicit discussion of subsidies and insurance mechanisms as alternative policy instruments to restore an efficient and joint utility maximizing policy. While tradable deficit permits and negative prizes have been analyzed in specific contexts, to the best of our knowledge, no other paper has looked at subsidies and insurance schemes to induce policy reforms before, nor discussed their relative merits or implementability.

We part from the literature in several aspects. While the policy spillovers that we concentrate on could also be interpreted as "learning" from observing what other countries have done, we do not explicitly model a process of learning or updating of beliefs about how policies affect the domestic or other economies. We rather have a process in mind in which countries implement their policies simultaneously or without observing the impact of a particular policy on other economies. Moreover, we look at aggregate reforms and abstract from distributional effects within a country, political incentives to over- or under-reform, or asymmetric information. These effects are left for future work.

\section{Cooperative and non-cooperative policy}

\subsection{The basic model}

Our formal model looks at the policy choice of a representative country. We consider $n$ symmetric countries that interact. Countries are indexed with $i$. In each country, there is an initial distortion $\theta$ leading to a loss in output that gives rise to the need for economic reform $e_{i}$. One may think of $\theta$ as a business cycle phenomenon or a distortion in the supply of physical or human capital. In the first interpretation, a reform aims at increasing aggregate demand or investment and thus could be seen as a measure of fiscal policy. In the second interpretation, a government will need to implement 
supply side policies that raise productivity or factor supply and the reform can be understood as deregulation in labor or product markets. What is crucial is that the government does not know ex-ante whether a specific policy will achieve the goal and to what extent. We assume that $\tilde{\eta}_{i}$ measures the stochastic effectiveness of reform $e_{i}$ and that $\tilde{\eta}_{i}$ are i.i.d. with expected value $E\left(\tilde{\eta}_{i}\right)>0$ and variance $\sigma_{\eta}^{2}$ that is equal across countries.

There are spillovers from the policy reforms of one country on the output of other countries (see, e.g., Rodrik, 2014). This could be a spillover from an increase in investment or aggregate demand, from trade reform or an increase in employment that raises output in other countries. ${ }^{2}$ Spillovers are captured by a stochastic parameter $\tilde{\gamma}_{i j}$, measuring how a reform in country $j$ affects country $i$ 's output. Countries are uncertain about the size of the spillover. The stochastic spillovers are i.i.d. with $E\left(\tilde{\gamma}_{i j}\right)>0$ and variance $\sigma_{\gamma}^{2}$.

With respect to the effectiveness of reforms, we assume that a country's reform efforts will, on average, have a stronger effect on its output than the policy efforts of any other country via spillovers $E\left(\tilde{\eta}_{i}\right)>E\left(\tilde{\gamma}_{i j}\right)$, and that the realizations of the two stochastic parameters are independent $\operatorname{Cov}\left(\tilde{\eta}_{i}, \tilde{\gamma}_{i j}\right)=$ 0 . While the former assumption seems natural, one justification for the latter assumption is that even similar policies do not have necessarily the same consequences in both countries because of different institutional systems.

Finally, we assume that there are political or psychological costs of reforms $\alpha \geq 0$. The population or politicians may be averse to reforms simply because they create uncertainty, government may resist reforms because they are likely to hurt politically important special interest groups (Potters and Sloof, 1996; Grossman and Helpman, 2001), or there may be adverse psychological or health effects from large scale economic reforms (Djankov et al., 2016).

\footnotetext{
${ }^{2}$ Learning from policy reforms of other countries might be another spillover but, as we argued above, learning is not pursued here.
} 
Formally, with $n$ countries output of a single country follows:

$$
x_{i}=x_{i}^{*}-\theta+\tilde{\eta}_{i} e_{i}+\sum_{j=1, j \neq i}^{n} \tilde{\gamma}_{i j} e_{j},
$$

where we let $x_{i}$ be the current output of a country $i, x_{i}^{*}$ the desired output, and as described above, $\theta$ the output distortion, $\tilde{\eta}_{i}$ the effectiveness of policy reform $e_{i}$, and $\tilde{\gamma}_{i j}$ the spillover effect. Government's preferences (expressed as expected losses) are defined over deviations of output from the desired level $x_{i}^{*}$ and the costs of policy experiments:

$$
E V_{i}=E\left[\left(x_{i}-x_{i}^{*}\right)^{2}+\alpha e_{i}^{2}\right] .
$$

The time structure without policy instruments that correct for uncoordinated policy outcomes is:

1. The distortion $\theta$ is observed in each country.

2. National policy experiments $e_{i}$ are implemented.

3. The outcome of domestic and foreign experiments, $\tilde{\eta}_{i}$ and $\tilde{\gamma}_{i j}$, is realized and observed by all players.

4. Output $x_{i}$ and government utility $V_{i}$ are realized.

For the case where we analyze subsidies as a policy instrument to correct for uncoordinated outcomes, they are paid out after step (1). For the analysis of an insurance mechanism, the sequence of events is altered such that after step (3) transfers are paid. Throughout we focus on symmetric equilibria.

\subsection{Non-cooperative policy}

All $n$ countries simultaneously choose their optimal levels of reform $e_{i}$, given the choices of the $(n-1)$ other countries $e_{j}$ by minimizing (2). The 
first order condition for country $i$ is given as

$$
2\left(-\theta+\tilde{\eta}_{i} e_{i}+\sum_{j=1, j \neq i}^{n} \tilde{\gamma}_{i j} e_{j}\right) \tilde{\eta}_{i}+2 \alpha e_{i}=0 .
$$

Taking expectations and solving for $n$ countries gives the symmetric Nash solution as

$$
e(N a s h)=\frac{\theta \eta}{\alpha+\sigma_{\eta}^{2}+\eta(\eta+(n-1) \gamma)},
$$

where we dropped the index $i$ because of symmetry.

Effort is increasing in the degree of the initial distortion $\theta$. Not surprisingly, reform efforts are falling in the government's aversion to reforms $\alpha$, in the uncertainty about its outcome $\sigma_{\eta}^{2}$, and in the expected positive spillover from foreign reforms $\gamma$. The latter is magnified by the number of countries $n-1$, reflecting the incentive to free-ride on the efforts of all other countries. The influence of the expected effectiveness $\eta$ of domestic reforms on the level of reforms is positive if $\alpha+\sigma_{\eta}^{2}>\eta^{2}$. For a given average realization of the reform effectiveness, the reforms have to be sufficiently costly to the government or sufficiently uncertain so that a larger effectiveness of reforms actually leads to more reform efforts. Otherwise, a non-cooperative government reduces its reform efforts as policy becomes more effective in reducing the output distortion.

\subsection{Cooperative policy}

Having derived our benchmark case of non-cooperative policies, we next consider cooperative policies that maximize joint utility of all countries by taking spillovers into account. Formally, this requires minimizing a loss function

$$
E V=\sum_{i=1}^{n} E\left[\left(-\theta+\tilde{\eta}_{i} e_{i}+\sum_{j=1, j \neq i}^{n} \tilde{\gamma}_{i j} e_{j}\right)^{2}+\alpha e_{i}^{2}\right]
$$

with respect to the choices of $e_{i}$ for all $n$ countries. We get $i=1, \ldots, n$ first 
order conditions of the form

$$
\begin{gathered}
2\left(-\theta+\tilde{\eta}_{i} e_{i}+\sum_{j=1, j \neq i}^{n} \tilde{\gamma}_{i j} e_{j}\right) \tilde{\eta}_{i}+2 \alpha e_{i} \\
+2 \sum_{j=1, j \neq i}^{n} \tilde{\gamma}_{j i}\left(-\theta+\tilde{\eta}_{j} e_{j}+\tilde{\gamma}_{j i} e_{i}+\sum_{k=1, k \neq i, j}^{n} \tilde{\gamma}_{j k} e_{k}\right)=0 .
\end{gathered}
$$

In contrast to non-cooperative policy making, joint optimization takes into account that domestic reforms have a positive output effect on all other countries. This spillover can be decomposed into an effect where country $i$ 's reform "directly" increases the output in country $j$ and, in addition, "indirectly" increases the output in country $j$ via positive output effects in all other countries $k$ that feed back into country $j$.

Solving for $n$ symmetric countries gives optimal efforts as

$$
e(\text { Coop })=\frac{\theta(\eta+(n-1) \gamma)}{\alpha+\sigma_{\eta}^{2}+(n-1) \sigma_{\gamma}^{2}+(\eta+(n-1) \gamma)^{2}} .
$$

There are two differences as compared to the case of non-cooperative policy setting. First, there is an expected positive effect on reforms from taking the positive effect on other countries into account, denoted by the second term in the numerator. This effect is increasing in the size of the initial distortions $\theta$ because reforms become more necessary, and it is also increasing in the number of countries $n-1$ to which this policy spills over. There is also a negative influence from spillovers as their influence is uncertain and may therefore cause additional output fluctuations, captured by $(n-1) \sigma_{\gamma}^{2}$ in the denominator. The variance of the spillover is taken into account in the cooperative solution but not in the non-cooperative solution.

These two opposing influences have to be weighed against each other to see under what circumstances there will be more policy reforms in the cooperative solution. From comparing (4) and (7), we find that there are 
more policy reforms under cooperation than under non-cooperation if

$$
\frac{\alpha+\sigma_{\eta}^{2}}{\eta}>\frac{\sigma_{\gamma}^{2}}{\gamma}
$$

Uncertainty about the spillover relative to its average effect has to be small enough for the cooperative solution to lead to more policy reforms. Otherwise an increase of policy reforms risks to cause higher output variability in other countries. Cooperation will also lead to more reforms if single countries are strongly averse against reforms or if the outcome of domestic policy reforms is highly uncertain in relation to their expected effectiveness.

\section{Instruments to correct for non-cooperative policy outcomes}

After having established that the non-cooperative solution will often lead to an inefficient level of policy reforms, the question is whether mechanisms can be created that yield the efficient solution. The obvious way, of course, would be to set policies jointly as the cooperative solution assumes. In many cases, however, full integration of policies may not be a feasible option, nor may it be necessarily desirable. There often is public or political resistance against transferring competences and policy decisions to a central government. There are various examples related to the process of European integration such as joint taxation, a common fiscal policy, external relations, or a common social policy where a cooperative solution in the sense that policy decisions are shifted to "Brussels" is not supported by national governments and their electorates (Borrás and Jacobsson, 2004).

However, alternative and more indirect policy instruments achieving similar positive outcomes might be able to substitute for centralization, and we analyze two such potentially feasible policies in the following two subsections. We begin with the instrument of subsidies. Here, the idea is that governments collect and pool fiscal resources ex-ante and pay out subsidies to those countries undertaking policy reforms according to their measurable efforts. The more reforms are undertaken, the more money is handed out to 
the respective country. This can serve to compensate for possibly negative output effects of reforms and for the non-pecuniary costs of reforms. In the next step, we look at ex-post redistribution of fiscal resources among countries. Countries continue to undertake policy reforms independently from each other but they are insured against bad outcomes. Those faring worse than their partners receive compensation, those faring better support them. Once we have introduced and analyzed the instruments, we proceed to discuss which of the two mechanisms is superior in terms of implementation requirements.

\subsection{Subsidies}

We assume that first tax contributions $t_{i}$ are collected from all governments with equal shares $t$ which then are used to finance subsidies $\mu^{S u b}$, paid proportional to individual reform efforts $e_{i}$. The overall budget constraint is given by

$$
n t=\mu^{S u b} \sum_{i=1}^{n} e_{i} .
$$

The ex-post net transfer to country $i$ can be written as

$$
T_{i}^{S u b}=\mu^{S u b} e_{i}-\frac{\mu^{S u b}}{n} \sum_{i=1}^{n} e_{i}
$$

where countries obtain funds for their policy reforms but also have to contribute ex-ante to the common pool to finance the subsidies to themselves and other countries. Expected losses for country $i$ (and analogously for all other $n-1$ countries) with a subsidy scheme become

$$
E V_{i}(S u b)=E\left[\left(-\theta+\tilde{\eta}_{i} e_{i}+T_{i}^{S u b}+\sum_{j=1, j \neq i}^{n} \tilde{\gamma}_{i j} e_{j}\right)^{2}+\alpha e_{i}^{2}\right],
$$

where we express the transfer in output terms.

The optimal amount of policy reforms for a single government follows as

$$
e(S u b)=\frac{\theta\left(\eta+\frac{n-1}{n} \mu^{S u b}\right)}{\alpha+\sigma_{\eta}^{2}+\left(\eta+\frac{n-1}{n} \mu^{S u b}\right)(\eta+(n-1) \gamma)} .
$$


The influence of subsidies on the policy choice of national governments is twofold: On the one hand, they increase reforms because those are subsidized, thus leveraging the influence of the initial distortion $\theta$. On the other hand, countries realize that more reforms lead to more efforts in other countries that create positive spillovers and thus allow to lower own efforts. Comparative statics show that the net-effect of an increase of subsidies on reform efforts is clearly positive.

But what level of subsidies $\mu$ are needed to restore the efficient level of policy reforms? Setting (7) equal to (12) and solving for $\mu^{\text {Sub }}$, we get

$$
\mu^{S u b}=n \frac{\gamma\left(\sigma_{\eta}^{2}+\alpha\right)-\eta \sigma_{\gamma}^{2}}{\alpha+\sigma_{\eta}^{2}+(n-1) \sigma_{\gamma}^{2}} .
$$

We already know that optimal subsidies are positive if condition (8) is fulfilled and which reappears in the numerator. That is, if the cooperative solution yields more policy reforms than what a single country would opt for, a subsidy of size $\mu^{S u b}$ will induce more reforms. Subsidies help to overcome the initial resistance against reforms due to reform aversion and the influence of their uncertainty that made countries hesitant to reform in the first place. Should the cooperative solution require less policy reforms than what a single country will implement, the required subsidy has to be negative - single countries' reform efforts actually need to be taxed and the revenues should be redistributed on a per country basis.

Comparative statics show that, quite intuitively, more subsidies should be paid out as the spillover $\gamma$ is on average larger and the effect of the policy changes on a country's own output $\eta$ lower. Similarly, if a single country does too little policy reforms because it is uncertain about its outcomes $\left(\sigma_{\eta}^{2}\right)$ or has high marginal costs of reform $(\alpha)$, a higher subsidy is needed to correct for this. However, there should be lower subsidies for reforms if the uncertainty of spillover effects $\left(\sigma_{\gamma}^{2}\right)$ is large because it is no longer certain that policy changes are actually helpful for other countries. Finally, the effect of the number of countries $n$ is ambiguous. More countries imply more spillovers and thus the incentive to use subsidies to benefit from more spillovers increases. If, at the same time, those spillovers are uncertain, 
more reforms create more variability in more countries which makes them less attractive to be supported by subsidies. Thus, subsidies are increasing in the number of countries only if $\alpha+\sigma_{\eta}^{2}>\sigma_{\gamma}^{2}$.

\subsection{Insurance}

We next turn to an alternative scheme which insures countries against unfavorable reform outcomes. For any kind of insurance to make sense, of course, countries must be aware that not all spillovers and reform outcomes are identical, even if their expected values are and if this should be the case in equilibrium. We consider an insurance scheme that compensates for ex-post deviations from a common mean of policy outcomes by a transfer $T_{i}^{\text {Insu }}$ :

$$
T_{i}^{I n s u}=\mu^{I n s u}\left(\frac{1}{n} \sum_{i=1}^{n} \tilde{\eta}_{i}-\tilde{\eta}_{i}\right)
$$

where payments to or from country $i$ depend just on the potentially different national realizations of $\tilde{\eta}_{i}$. Note that only the effectiveness $\tilde{\eta}_{i}$ of "per unit of reform" is insured because insuring policy and its outcome $\tilde{\eta}_{i} e_{i}$ would create an obvious moral hazard problem. ${ }^{3}$ This requires that the effectiveness of reforms is measurable and that only outcomes below average outcome for the same level of reform lead to transfers from the other members of the insurance pool. The parameter $\mu^{I n s u}$ measures to what extent deviations in a country's reform effectiveness from the average translate into payments out of or into the insurance pool. The sum of all (positive or negative transfers $T_{i}^{I n s u}$ ) need to net out to zero so that the budget constraint fulfills

$$
\sum_{i=1}^{n} T_{i}^{\text {Insu }}=0
$$

Again interpreting the transfers $T_{i}^{I n s u}$ in output units, country $i$ 's expected

\footnotetext{
${ }^{3}$ This would also be the case if payment would be conditional on output levels and thus policy outcomes instead of policy reforms undertaken. Whenever payments depend on policy efforts, there is an incentive to reform less in order to obtain higher payments.
} 
losses become

$$
E V_{i}(\text { Insu })=E\left[\left(-\theta+\tilde{\eta}_{i} e_{i}+T_{i}^{I n s u}+\sum_{j=1, j \neq i}^{n} \tilde{\gamma}_{i j} e_{j}\right)^{2}+\alpha e_{i}^{2}\right] .
$$

Optimal policy follows as

$$
e(\text { Insu })=\frac{\theta \eta+\mu^{\operatorname{Insu} \frac{n-1}{n} \sigma_{\eta}^{2}}}{\alpha+\sigma_{\eta}^{2}+\eta(\eta+(n-1) \gamma)} .
$$

The insurance mechanism, indeed, induces governments to implement more policy reforms. However, since the insurance is only paid in case of "bad" outcomes and not ex-ante, its only influence on reform is via the uncertainty of domestic reforms on output $\sigma_{\eta}^{2}$. The higher is the variance of outcome from domestic reforms, the more valuable insurance becomes, leading to more reforms. The other channels that determine policy experiments in the non-cooperative case are not influenced by this type of insurance.

Again, we can explore how generous the level of insurance has to be to reach the efficient level of reforms. By equating (17) with (7), the necessary insurance is given as

$$
\mu^{\text {Insu }}=\frac{n \theta\left(\gamma\left(\alpha+\sigma_{\eta}^{2}\right)-\sigma_{\gamma}^{2} \eta\right)}{\sigma_{\eta}^{2}\left(\alpha+\sigma_{\eta}^{2}+(n-1) \sigma_{\gamma}^{2}+(\eta+(n-1) \gamma)^{2}\right)} .
$$

Like in the case of subsidies, the transfer out of the insurance pool needs to be positive if a country falls short in its reform effectiveness relative to average, that is, if condition (8) is fulfilled. In the other case, where noncooperation leads to too many reforms, insurance would take the form of a tax on the success of policy reforms.

Comparative statics show that the necessary degree of insurance to establish the cooperative level of policy reforms is increasing in the countries' aversion to reform $(\alpha)$ and the variability of domestic reforms $\left(\sigma_{\eta}^{2}\right)$, but falling in the uncertainty about spillovers $\left(\sigma_{\gamma}^{2}\right)$. The reason is that insurance shall overcome aversion to reforms, but if spillovers are highly uncertain, insurance should not induce too many reforms. Insurance is also decreasing 
in the effectiveness of domestic reforms $(\eta)$ if condition (8) is fulfilled. If non-cooperative reforms are too low, less incentives are needed to increase them if their effectiveness is high. The size of the spillover $\gamma$ and the number of countries $n$ have ambiguous comparative static influences on $\mu^{\text {Insu }}$. They both tend to have a positive effect on insurance, however, if the resistance to and the variability of domestic reforms $\left(\alpha\right.$ and $\left.\sigma_{\eta}^{2}\right)$ are sufficiently large compared to the size and uncertainty of the spillover $\left(\gamma\right.$ and $\left.\sigma_{\gamma}^{2}\right)$.

\subsection{Discussion}

Given that both policy instruments can restore policy reforms to an efficient level, the question arises which one is preferable. One criterion of assessment could be the level of redistribution involved among the countries participating in the mechanism. But given that all countries are symmetric, there is no redistribution among them on average and we do not discuss this issue further.

Another aspect when comparing the insurance mechanism with the subsidy is which mechanism is easier to implement. For the subsidy one needs credible and verifiable information on the amount of reforms that a country implements. If this piece of information is not acquirable or reform efforts could not be measured sufficiently accurately, a moral hazard problem would arise with the subsidy mechanism. While it is certainly difficult to rule out any sort of moral hazard problem, in fact a large body of literature deals with this phenomenon in the context of fiscal federalism (see, e.g., Persson and Tabellini, 1996), and there are examples related to the process of European integration where policies have been earmarked to the fulfillment of particular benchmarks. Most recently, in the realm of the sovereign debt crisis, transfers to Greece have been conditioned on the fulfillment of predefined structural reforms with the International Monetary Fund (IMF), the European Central Bank, and the European Commission documenting the progress made. Similarly, the European Growth and Stability Pact, labor market reforms in the framework of the open-method of coordination, or the correct distribution of cohesion funds which typically comes with cofinancing obligations of the recipients require the measurement of policies on 
the part of the member countries. Thus, we would argue that at least in the European Union case, mechanisms to provide such information do already exist, even if they are certainly not immune from manipulation.

For the insurance mechanism to work, one needs information on its marginal contribution $\eta$ to increase output per "unit of reforms". This additional piece of information is probably more difficult to come by than how much reforms were undertaken or how many resources were spent on the policy reform. It would actually require that one be able to assess the marginal effect of each policy reform on output which is probably much harder to establish empirically. Moreover, the insurance scheme, contrary to subsidies, requires information on the exact size of the output gap $\theta$ as the comparisons of (13) and (18) shows. Therefore the informational requirement for this mechanism are even larger.

Additionally, we believe that ex-ante subsidies are the better scheme than insuring ex-post differences because countries, once reform effectiveness has been revealed, have an incentive to renege on their promise to contribute to the insurance pool if they do better than the average country. Since subsidies and the per country contributions financing the scheme are paid when reform packages are actually installed, but before their effectiveness is revealed, they do not have this time-consistency problem.

Our conclusion would hence be that even though subsidies are probably not able to solve the moral hazard problem completely, those problems are likely to be even larger with insurance because of the higher informational requirements. Moreover, the European Union and international organizations like the IMF already have procedures in place that observe and measure policies and their outcomes in their member states, and that could be adapted to conditionally subsidize policy reforms.

\section{Conclusions}

When countries need to implement costly economic policy reforms, these often entail uncertainties about their effectiveness for the home country as well as about their spillovers to other countries. Due to the spillovers, reform efforts will not be optimal in a non-cooperative policy setting and con- 
sequently there will either be too few or too many policy changes. While policy centralization is a way of taking these spillovers into account, real world examples like the European Union or supranational fora like the G-20 demonstrate that national governments are hesitant to shift policy making to a central unit. Therefore, alternative instruments may be more promising to lead national governments to set the efficient level of economic policy reforms. We suggest and compare two such mechanisms in a setting where national governments set inefficient levels of reform with respect to a cooperative solution.

We find that policy spillovers may lead to too few reform efforts by the countries involved. If uncertainties with respect to the effects of the spillovers become too large, however, it may be the case that countries are actually reforming too much if compared to the socially optimal reform level. Next, we have shown that both of the policy instruments, subsidies or an insurance scheme, can achieve the efficient level of policy reforms. In a world where national governments reform too little, subsidies and a redistribution scheme which reallocates resources according to the outcome of a given policy can increase reform efforts to the efficient level. Both instruments also work for the case where national governments reform too much. Here, the subsidy turns into a tax whose revenues are redistributed among the countries in equal shares, and similarly the insurance payment becomes a tax. We also argue that subsidies are advantageous because less information is required than for insurance. Overall, our results suggests that coordination of policies can be achieved by setting the right kind of incentives and does not necessarily need centralization.

In our set-up we abstracted from modeling asymmetric information on actually undertaken reforms. By not dealing with issues of moral hazard we were able to focus on the consequences of uncertainty on reform effects and possible mechanisms to restore efficiency In future work, it would be interesting to look at asymmetric information in a discussion of appropriate mechanisms to induce optimal reform efforts, and how countries could be induced to reveal their true needs for reform and their effects. 


\section{References}

Alesina, A. And A. Drazen (1991): "Why are stabilizations delayed?" American Economic Review, 81, 1170-88.

Angeloni, I. And J. Pisani-Ferry (2012): "The G20: Characters in search of an author," Bruegel Working Paper.

BABeckỳ, J. And N. F. CAmpos (2011): "Does reform work? An econometric survey of the reform-growth puzzle," Journal of Comparative Economics, 39, 140-158.

Bala, V. And S. Goyal (1998): "Learning from neighbours," The Review of Economic Studies, 65, 595-621.

Bolton, P. And C. HARRIS (1999): "Strategic experimentation," Econometrica, 67, 349-374.

Borrás, S. AND K. JACOBSSON (2004): "The open method of co-ordination and new governance patterns in the EU," Journal of European Public Policy, 11, 185-208.

Brezis, E. S. AND T. Verdier (2003): "Political institutions and economic reforms in Central and Eastern Europe: a snowball effect," Economic Systems, 27, 289-311.

Cai, H., D. Treisman, et AL. (2009): "Political decentralization and policy experimentation," Quarterly Journal of Political Science, 4, 35-58.

Callander, S. and B. Harstad (2015): "Experimentation in federal systems," The Quarterly Journal of Economics, 130, 951-1002.

Casella, A. (1999): "Tradable deficit permits: efficient implementation of the Stability Pact in the European Monetary Union," Economic Policy, $14,321-362$.

(2001): "Market mechanisms for policy decisions: Tools for the European Union," European Economic Review, 45, 995-1006. 
Coe, D. T. And D. J. Snower (1997): "Policy complementarities: The case for fundamental labor market reform," Staff Papers-International Monetary Fund, 1-35.

Dewatripont, M. And G. Roland (1995): "The design of reform packages under uncertainty," The American Economic Review, 1207-1223.

Djankov, S., E. Nikolova, And J. Zilinsky (2016): "The happiness gap in Eastern Europe," Journal of Comparative Economics, 44, 108-124.

Fernandez, R. And D. Rodrik (1991): "Resistance to reform: status quo bias in the presence of individual-specific uncertainty," The American Economic Review, 1146-1155.

Fidrmuc, J. And E. KARAJA (2013): "Uncertainty, informational spillovers and policy reform: A gravity model approach," European Journal of Political Economy, 32, 182-192.

Freeman, R. B. (2005): "Labour market institutions without blinders: The debate over flexibility and labour market performance," International Economic Journal, 19, 129-145.

Gassebner, M., N. Gaston, And M. J. Lamla (2011): "The inverse domino effect: Are economic reforms contagious?" International Economic Review, 52, 183-200.

Gilardi, F. (2010): "Who learns from what in policy diffusion processes?" American Journal of Political Science, 54, 650-666.

Grossman, G. M. And E. Helpman (2001): Special interest politics, Cambridge, Massachusetts: MIT press.

Keller, G., S. Rady, And M. CRIPPS (2005): "Strategic experimentation with exponential bandits," Econometrica, 73, 39-68.

Kerber, W. And M. Eckardt (2007): "Policy learning in Europe: The open method of co-ordination and laboratory federalism," Journal of European Public Policy, 14, 227-247. 
Kotsogiannis, C. and R. Schwager (2006a): "On the incentives to experiment in federations," Journal of Urban Economics, 60, 484-497. (2006b): "Political uncertainty and policy innovation," Journal of Public Economic Theory, 8, 779-805.

Meseguer, C. (2006): "Learning and economic policy choices," European Journal of Political Economy, 22, 156-178.

Mukand, S. W. And D. Rodrik (2005): "In search of the holy grail: Policy convergence, experimentation, and economic performance," The American Economic Review, 95, 374-383.

Persson, T. and G. Tabellini (1996): "Federal fiscal constitutions: Risk sharing and moral hazard," Econometrica, 64, 623-646.

Potters, J. And R. Sloof (1996): "Interest groups: A survey of empirical models that try to assess their influence," European Journal of Political Economy, 12, 403-442.

RINCKE, J. (2009): "Yardstick competition and public sector innovation," International Tax and Public Finance, 16, 337-361.

RoDRIK, D. (2014): "When ideas trump interests: preferences, worldviews, and policy innovations," The Journal of Economic Perspectives, 28, 189208.

Roland, G. (2000): Transition and Economics: Politics, Markets, and Firms, Cambridge, Massachusetts: MIT press.

Rose-Ackerman, S. (1980): "Risk taking and reelection: Does federalism promote innovation?" The Journal of Legal Studies, 593-616.

SaAm, N. J. And W. Kerber (2013): "Policy innovation, decentralised experimentation, and laboratory federalism," Journal of Artificial Societies and Social Simulation, 16, 7.

Strumpf, K. S. (2002): "Does government decentralization increase policy innovation?" Journal of Public Economic Theory, 4, 207-241. 
TANZI, V. (2008): "The future of fiscal federalism," European Journal of Political Economy 24.3 : 705-712.

Tommasi, M. And A. Velasco (1996): "Where are we in the political economy of reform?" The Journal of Policy Reform, 1, 187-238.

Volden, C., M. M. Ting, and D. P. Carpenter (2008): "A formal model of learning and policy diffusion," American Political Science Review, $102,319-332$. 